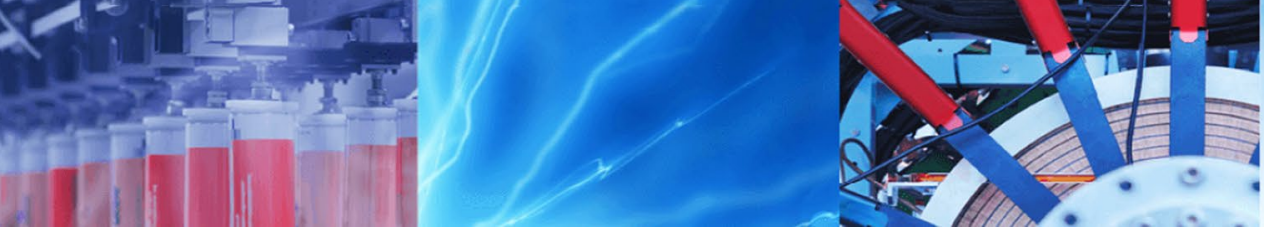

Research Article

\title{
Geospatial analysis of the depletion of surface water body and floodplains in Dhaka City (1967 to 2008) and its implications for earthquake vulnerability
}

\author{
Siddhartho Shekhar Paul ${ }^{1,2}$ (D) Syed Humayun Akhter ${ }^{2} \cdot$ Khaled Hasan $^{2,3} \cdot$ Md. Zillur Rahman ${ }^{2}$
}

(c) Springer Nature Switzerland AG 2019

\begin{abstract}
Dhaka city the capital of Bangladesh experienced unprecedented urban growth since the country's independence in 1971. A significant portion of the urbanization took place in the encroached surface water body and floodplain (SWB and FP) areas. We thus aimed to capture the depletion of SWB and FP in Dhaka city from 1967 to 2008 using geospatial analysis and evaluated its implications for earthquake vulnerability. We used CORONA (1967) and QuickBird (2008) satellite images to compare the pre- and post-urbanization status of SWB and FP. We identified a striking change occurred during this period with a total loss of $33 \%$ of SWB and FP areas. The channelized water body faced a depletion of $15 \%$, while the open water body which mainly includes the floodplains experienced a loss of $38 \%$. The urban structures built on the depleted SWB and FP are highly vulnerable to ground motion and liquefaction of earthquake. We found that $90 \%$ of the depleted areas have a shear wave velocity in the top $30 \mathrm{~m}$ of soil thickness (Vs30) of $180-360 \mathrm{~m} / \mathrm{s}$, while the rest has a Vs30 value of $<180 \mathrm{~m} / \mathrm{s}$. Additionally, $60 \%$ of the depleted areas have liquefaction potential index (LPI) ranging from 5 to $>15$. We produced an earthquake vulnerability map based on the information of surficial geology, Vs30, LPI and found that substantial areas near the southern, eastern, and western boundaries of the city scored highly in the vulnerability map. The results of the study can support formulation of rational earthquake preparedness strategy for Dhaka.
\end{abstract}

Keywords CORONA · Liquefaction · QuickBird · Remote sensing · Shear wave velocity · Urbanization

\section{Introduction}

In the present time, large-scale urban expansion and changes in the natural landscapes are commonplace across the globe. But urban expansion is most evident in developing countries, particularly over the past several decades [1]. Encroachment of the natural surface water body and floodplains (SWB and FP) is among the obvious consequences of these widespread urban developments. Estimation says that $50 \%$ of the initial stock of earth's wetland has already been depleted [2]. Bangladesh which is one of the world's most densely populated countries completely complies with this global context. The burgeoning population and demand-driven urban growth have caused substantial alterations of the natural landscape of the country. Accordingly, Dhaka city-the capital of the country and center of its economic development-comprises the major share of this massive urban expansion and the associated depletion of the natural water body.

Pleistocene pop-up landscape of Dhaka city has become the main growth center of the country after its independence in 1971. The city comprises only an area of $336 \mathrm{~km}^{2}$, and its periphery is marked by an extensive river system which has constrained the physical expansion of the city. As a result, the city had to accommodate a substantial portion of its urban expansion on the encroached

$\triangle$ Siddhartho Shekhar Paul, siddpaul@mail.ubc.ca | ${ }^{1}$ Faculty of Land and Food Systems, University of British Columbia, 2357 Main Mall, Vancouver, BC V6T 1Z4, Canada. ${ }^{2}$ Department of Geology, University of Dhaka, Dhaka 1000, Bangladesh. ${ }^{3}$ Department of Geology, Austin Community College, 1218 West Ave, Austin, TX 78701, USA.

SN Applied Sciences (2019) 1:565 | https://doi.org/10.1007/s42452-019-0582-5

Received: 28 January 2019 / Accepted: 9 May 2019 / Published online: 14 May 2019 
land which was once part of the natural SWB and FP. In the recent past, the peripheral channel system was well connected with numerous canals and wetlands within the city forming a natural drainage basin [3]. The rapid and unplanned urban growth has substantially altered this natural drainage network and used the land for urban development causing a myriad of environmental issues including monsoonal waterlogging, flooding, decline in groundwater recharge, and loss of biodiversity [4, 5]. Monsoonal waterlogging and flooding are the most immediate and recurrent issues faced by the city, and thus, these remained the focus of most of the studies conducted during the past few years. However, artificial filling of the low-lying SWB and FP areas to build urban infrastructures poses a significant concern for earthquake-related disasters and that has not been widely studied by the researchers.

Bangladesh belongs to a highly active tectonic setting, and a recent study suggested that the presence of a locked megathrust plate boundary in this region has placed Bangladesh in risk for greater than 8 magnitude earthquakes [6]. In addition, the capital city, Dhaka was listed among the 20 most earthquake-vulnerable cities of the world due to the earthquake-prone tectonic settings of the country and poor urbanization practice of the city [7]. As expressed in many recent studies, Dhaka with its faulty urban development may face unforeseeable catastrophic conditions in the occurrence of high-magnitude ( 7.0 or higher on Richter scale) earthquakes, mainly due to the failure of urban structures [8]. How well the urban built-up structures perform during earthquakes primarily depends on the ground condition of the sites and the intensity of the ground motion experienced by the structures [9]. In the case of Dhaka, a substantial portion of the urban expansion occurred on the low-lying surface water areas and floodplains which were filled with soft sediments. Such site conditions may strongly amplify the amplitude of the ground motion exerted by earthquakes and cause structural failures, liquefaction, etc. [10]. Damages caused by the previous earthquakes in different cities of the world had a strong connection with similar site conditions. As a result, it is of high importance to identify the areas in Dhaka that were built over SWB and FP by comparing information from pre- and post-urbanized conditions.

Changes in the natural landscape and its conversion to other land use practices can effectively be assessed and monitored by the remote sensing techniques [11]. Geospatial analysis of the remotely sensed data (e.g., air photo, satellite image, etc.) representing different time periods provides a clear picture of the changes in the landscape features. The outrageous development in Dhaka started mostly after the independence of the country in 1971. Thus, analysis of the remote sensing data from pre-1971 to the recent time will provide an estimation of the depleted SWB and FP areas that were encroached for urban development. This study therefore utilized satellite images captured in 1967 and 2008 to identify the urbanization-induced depletion of SWB and FP in Dhaka city and then reviewed the associated earthquake vulnerability of the depleted areas using the existing literature and geospatial maps related to earthquake hazard. The outcomes of this research will help formulating a rational urban development strategy to support effective earthquake preparedness efforts in Dhaka.

\section{Materials and methods}

\subsection{Overview of Dhaka city}

The study area Dhaka city lies between longitude $90^{\circ} 20^{\prime} \mathrm{E}$ and $90^{\circ} 30^{\prime} \mathrm{E}$ and between latitude $23^{\circ} 40^{\prime} \mathrm{N}$ and $23^{\circ} 55^{\prime} \mathrm{N}$ (Fig. 1). The elevation of this slightly undulating flat area varies between 2 and $16 \mathrm{~m}$ above mean sea level with low-lying areas located mostly in the eastern and western fringes [12]. The general slope of the area is from the north to the southeast where the ground surface merges gently with the floodplains of the Buriganga river. Dhaka city with its current population of about 13 million comprises the major share of the urban population in Bangladesh [13]. Various socioeconomic and political factors have been contributing to the phenomenal growth of the city over the past several decades. As a result, Dhaka city experienced about 20 -fold expansion by its area in the last 50-60 years, while the increase in population is more than 25 times during the same period [14].

\subsection{Geospatial analysis}

Geospatial analysis of remotely sensed satellite data has become an effective tool for extracting land use and land cover (LULC) information. A spatiotemporal investigation using satellite images provides a unique inventory and monitoring of LULC changes $[11,15]$. We herein employed geospatial tools to assess the depletion of SWB and FP areas in Dhaka city from 1967 to 2008 and later reviewed its implications for the earthquake vulnerability of the city.

As the city experienced substantial urban growth after its independence in 1971, it was critical to select a satellite image from around 1971 to represent the initial condition of the urbanization. Besides, delineating the small-scale heterogeneities in the urban landscape and detection of the changes in surface water areas required high-resolution satellite images. But collecting high-resolution satellite data from around 1971 was significantly challenging since most of the publicly available high-resolution 


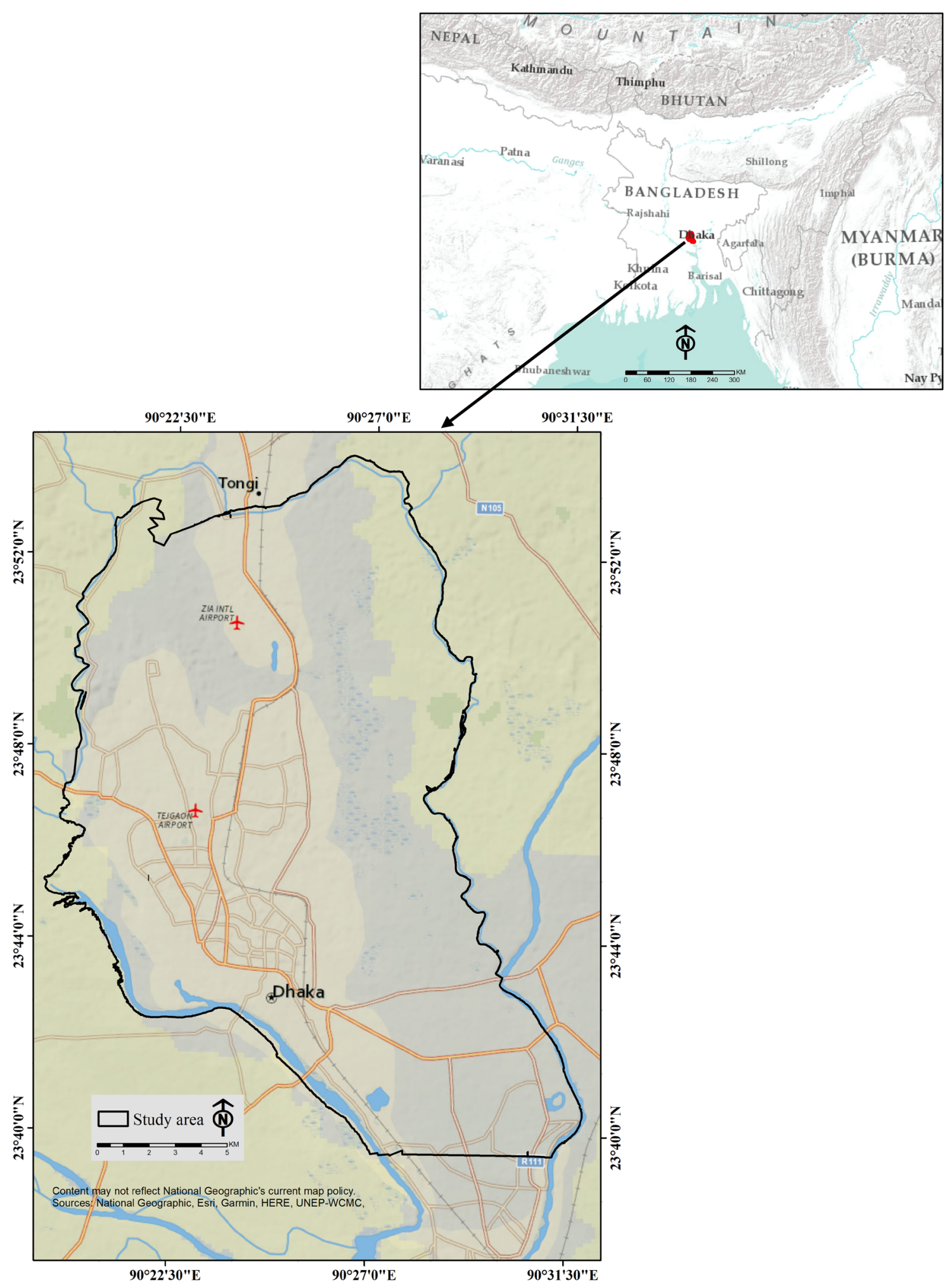

Fig. 1 Map showing the location of the study area, Dhaka city

sensors were launched after 2000. Finally, we were able to collect a CORONA satellite image of 8-m spatial resolution from 1967. We then obtained a QuickBird satellite image of 2.4-m resolution from 2008 to capture the posturbanized conditions. Both images were acquired from the Bangladesh Government's Center for Environmental and 
Table 1 Description of the satellite data used in this study

\begin{tabular}{llll}
\hline Data & $\begin{array}{l}\text { Acquisition time/ } \\
\text { date }\end{array}$ & Spatial resolution & $\begin{array}{l}\text { Spectral reso- } \\
\text { lution }\end{array}$ \\
\hline CORONA & 1967, Dry season & $8 \mathrm{~m} \times 8 \mathrm{~m}$ & Panchromatic \\
QuickBird & 2008, November & $2.4 \mathrm{~m} \times 2.4 \mathrm{~m}$ & Multispectral \\
\hline
\end{tabular}

Geographic Information Services (CEGIS). The images were captured in the dry season. Table 1 shows the description of the data.

We georectified the CORONA and QuickBird images using 20 ground control points (GCPs) which were recorded with a Trimble Differential Global Positioning System (DGPS) providing post-processing accuracies at the sub-meter level. The GCPs were spatially distributed across the study area. We used UTM Zone 46 N WGS 84 as the projection system and datum.

Unsupervised classification technique was used to extract the SWB and FP areas from the CORONA and QuickBird satellite images. The image pixels comprising the 'water' feature usually have distinct spectral characteristics and can easily be differentiated from other 'terrestrial' features [16]. Thus, we performed a simple unsupervised classification on both images using the Iterative Self-Organizing Data Analysis (ISODATA) algorithm and specified to iterate 25 times and generate 100 clusters. Once this automatic process was finished, we assigned the clusters to three categories-'water', 'non-water', and 'unknown' using the manual interpretation of the images. Then, the 'unknown' areas were masked out to create a new image. We ran the unsupervised classification on this new image, and similarly, 'water', 'non-water', and 'unknown' categories were determined. This process was repeated two more times when the number of 'unknown' pixels became negligible and difficult to identify. The 'water' areas determined from this classification process were combined to derive the images of SWB and FP areas in Dhaka city for the years 1967 and 2008. We reclassified these two SWB and FP images of 1967 and 2008 following the same ISODATA classification approach to differentiate the 'channelized water body' (CWB) comprising the peripheral and inland channels and 'open water body' (OWB) comprising the floodplains, lakes, ponds, etc. Finally, we performed some manual editing on the raster layers to incorporate some seasonal water bodies which were not detected by the automatic digital classification procedure. GIS analysis was then performed to compare the outputs and determine the lost SWB and FP areas in Dhaka city from 1967 to 2008.

In the next phase, we gathered relevant information on the regional tectonic setup and historical earthquake occurrences in Dhaka city and surrounding areas from published and gray literature as well as from the United States Geological Survey's (USGS) data warehouse. Maps of regional tectonic plate movements, faults, and lineaments, earthquake occurrences, and surficial geology were produced using this information. We also generated maps of earthquake-related hazards, i.e., ground shaking and liquefaction for the depleted SWB and FP areas using the maps extracted from [17] and [18], respectively. We then assigned vulnerability scores from 1 to 5 (' 1 ' being the least vulnerable) to the maps of surficial geology, ground motion, and liquefaction. A raster-based calculation was performed afterward to derive a map of earthquake vulnerability.

\section{Results and discussion}

\subsection{Surface water body and floodplains in 1967}

The analysis of the CORONA image found a total of $98.89 \mathrm{~km}^{2}$ of SWB and FP existed in Dhaka city in 1967. Floodplains were widely distributed along the eastern and western edges of the city (Fig. 2). In 1967, the western fringe of the city was occupied by the marshy low lands

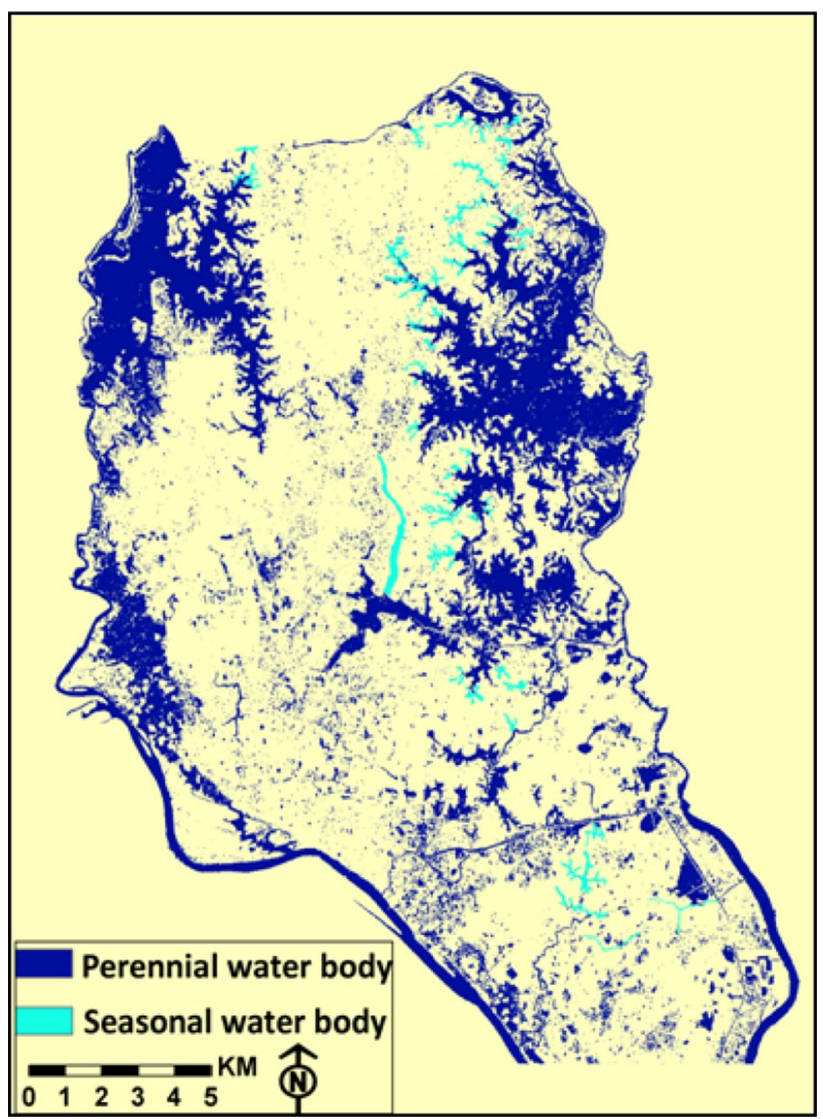

Fig. 2 Surface water body and floodplains in 1967 
of the floodplain of the Buriganga and Turag rivers, while the floodplain of the Balu river covered most of the eastern periphery of the city. There were an appreciable number of well-connected channels and canals throughout the city. The inland lakes, namely Gulshan-Banani lake, Dhanmondi lake, Ramna lake, as well as some of the major canals, namely Begunbari Khal, Dholai Khal, Hatir Jheel, etc., were connected to the floodplains of the peripheral rivers. There were some seasonal water bodies could also be identified although these seasonal water areas could be more precisely delineated if multiple images representing different seasons were available.

\subsection{Surface water body and floodplains in 2008}

We estimated the total area of Dhaka city's SWB and FP in 2008 as $66.04 \mathrm{~km}^{2}$ from the analysis of QuickBird satellite imagery. The analysis identified drastic depletion of floodplains in the eastern and western fringes of the city (Fig. 3). The well-connected drainage network of the city was found to be substantially altered in 2008. The floodplain areas were detected as sporadic and poorly connected waterways and marshes. Most of the inland

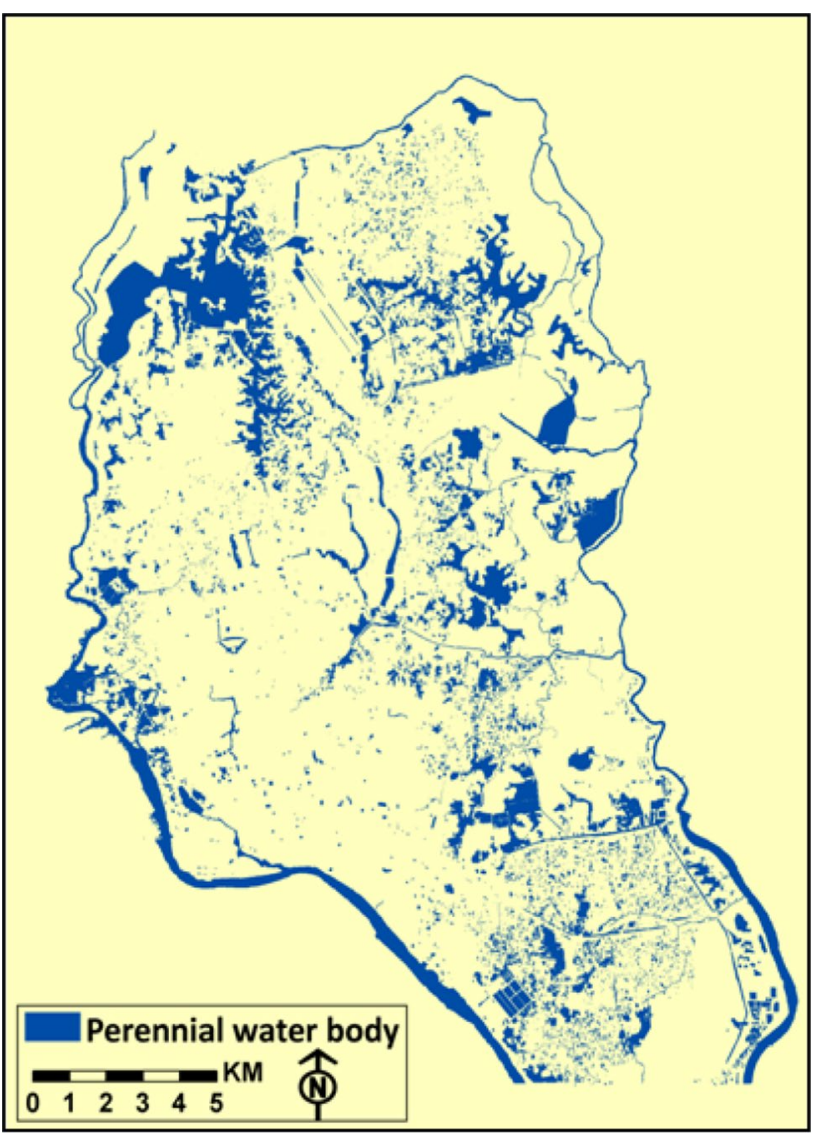

Fig. 3 Surface water body and floodplains in 2008 channels and canals were completely or partly disappeared in 2008. Dholai Khal in the old part of Dhaka city is one of the prominent canals that was entirely filled in and used for urban developments. The major inland lakes in the Gulshan, Banani, and Dhanmondi areas were partly encroached by the urban developers. The main course of the peripheral rivers was also affected and slightly shrunken from their previous extents.

\subsection{Changes in surface water body and floodplains from 1967 to 2008}

The present study revealed that Dhaka city lost a significant portion of its SWB and FP areas from 1967 to 2008. But the extent of the change is different for the peripheral channels and the floodplain areas. For better understanding, the study divided the total SWB and FP of the city into two groups-(i) 'channelized water body' (CWB) comprising the peripheral and inland channels and (ii) 'open water body' (OWB) comprising the floodplains, lakes, ponds, etc.

The CWB of Dhaka city included four peripheral channels, namely Buriganga river, Turag river, Balu river, and Tongi Khal. In 1967, these peripheral channels were found to be connected to many inland tributaries and/ or canals forming a well-defined network of channels throughout the city area. But a substantial portion of these inland channels was completely filled in or shrunken in 2008 causing a noticeable alteration of the connected channel network. Figure 4 shows the changes in the extent of the CWB between 1967 and 2008. It was also observed that the alterations of the main peripheral channels were not as dramatic as the inland channels indicating that the urbanization-induced encroachment was more intense in the inland areas than that in the peripheries. The total extent of the CWB was estimated as $17.56 \mathrm{~km}^{2}$ and $15.26 \mathrm{~km}^{2}$ in 1967 and 2008 , respectively, indicating a decline of $15 \%$.

On the other hand, the total extent of the OWB was $81.33 \mathrm{~km}^{2}$ in 1967 and $50.78 \mathrm{~km}^{2}$ in 2008, exhibiting a loss of $37.56 \%$ during the 41 years period. Figure 5 displays the changes in OWB extent. The most dramatic change in OWB occurred in the low-lying floodplain areas in the northeastern and northwestern part of the city. These include some of the most populated and desired neighborhoods of the present Dhaka city-Uttara, Mirpur, Mohammadpur, Bashundhara, etc. Some remarkable intrusions were also observed in the southern part of the city which represents the neighborhoods of Khilgaon, Aftabnagar, Demra, Jatrabari, etc. The wetlands in the Gulshan-Banani lake areas were also substantially encroached to promote extensive urban developments. 


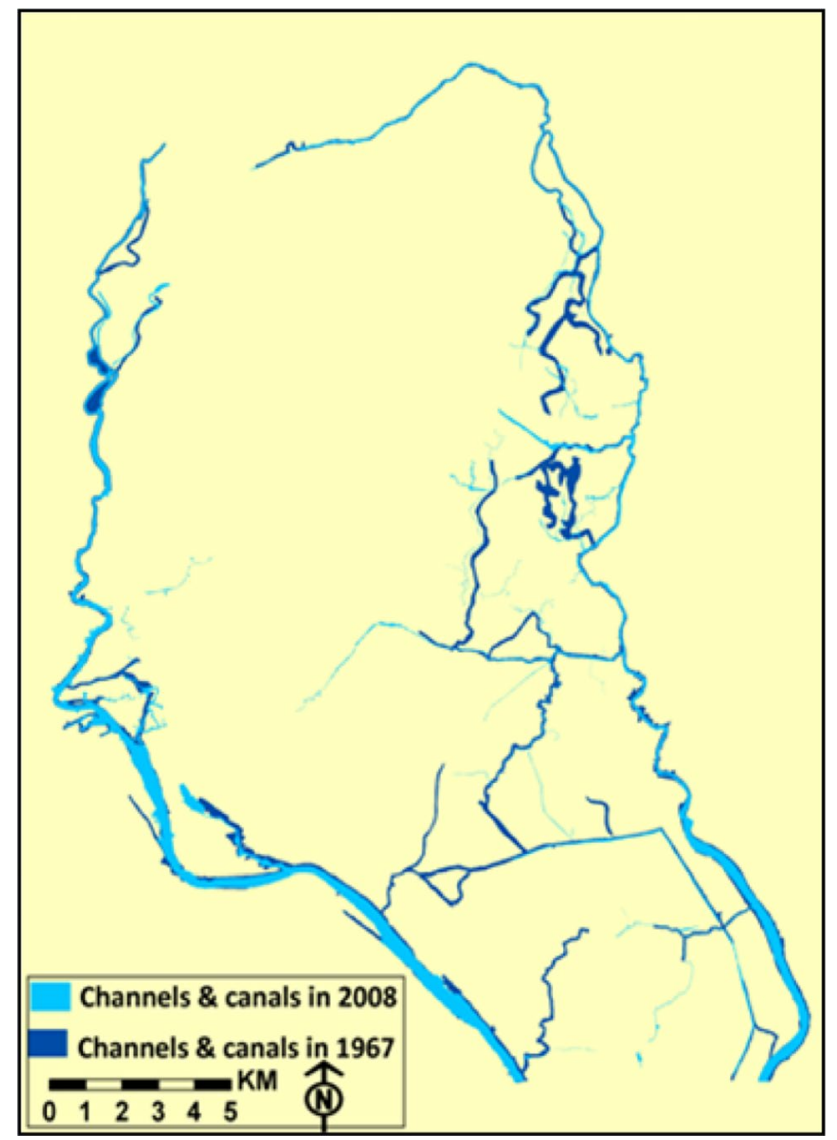

Fig. 4 Changes in the channelized water body (1967-2008)

\subsection{Implications for earthquake vulnerability}

\subsubsection{Susceptible regional and local tectonic settings}

Understanding of the earthquake hazard in Dhaka city is highly reliant on the assessment of the regional tectonic settings of Bangladesh as well as the local geology and the seismicity of the city. Bangladesh lies within a seismically active region due to its proximity to the meeting point of Indian, Eurasian, and Burmese (Myanmar) tectonic plates. In the north of Bangladesh, there is a continuous converging mechanism between Indian and Eurasian plates, while in the east, subduction mechanism occurs between Indian and Burmese plates [19]. The movement of Indian and Eurasian plates has been locked at the foot of the Himalayas for many years storing strain energy which may cause catastrophic earthquakes upon its release [6]. The occurrence of such earthquakes will have certain potential to devastate Bangladesh including the capital city Dhaka. In addition, there are several active regional fault systems, namely Himalayan front fault, Dauki fault, Naga thrust, faults in the Chittagong-Tripura fold belt, and Madhupur blind fault which are constantly contributing to the

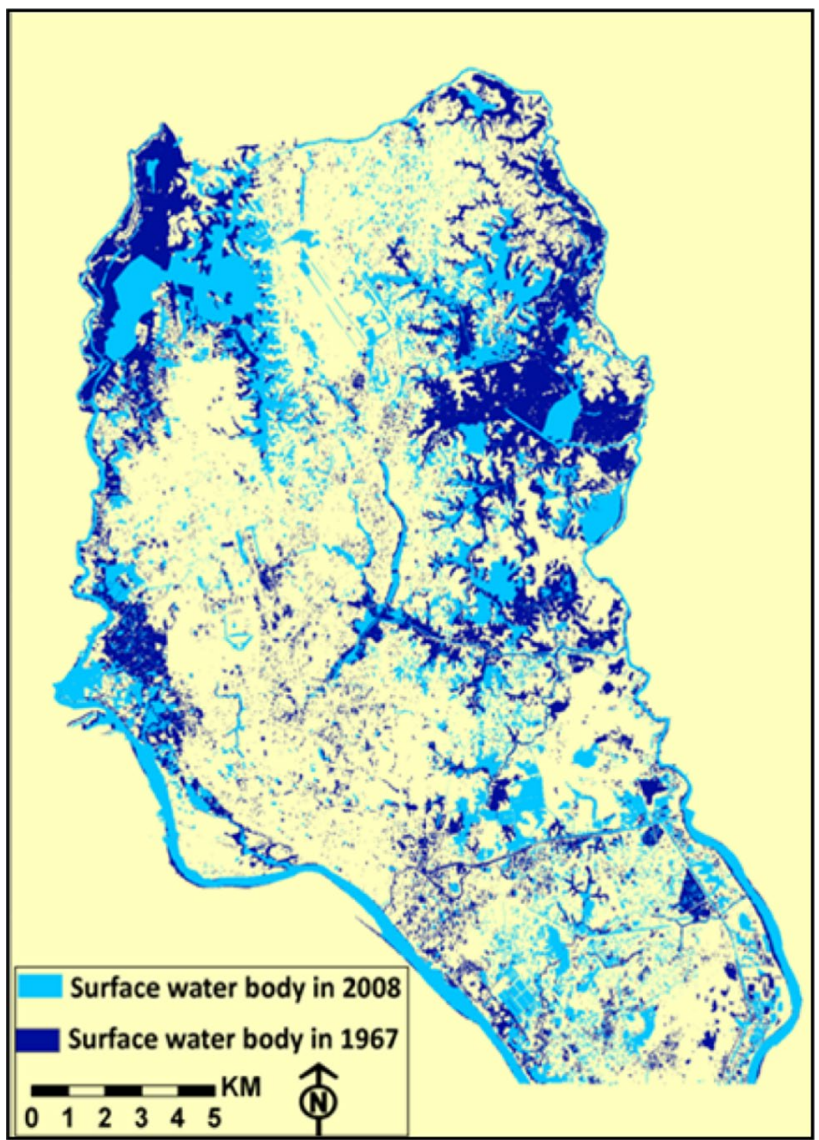

Fig. 5 Changes in the open water body (1967-2008)

earthquake occurrences in and around Bangladesh (Fig. 6) [19-21]. Any tectonic activities in these fault systems may cause significantly high-magnitude earthquakes in Bangladesh and affect Dhaka city.

The Madhupur fault system located in the middle of Bangladesh dominates the geological structure and tectonic characteristics in and around Dhaka city (Fig. 6). The city is an integral part of the Madhupur tract, which is an easterly tilted fault block and characterized by a number of small faults [23, 24]. Moreover, the shallow subsurface of Dhaka is marked by a number of faults and lineaments of variable dimensions and these are vulnerable to ground motion if coincide with the zones of high particle velocity [25] (Fig. 7). Due to this complex and active geological setup, Dhaka was jolted by several high- to moderatemagnitude earthquakes in the historical past, but the frequency of earthquake occurrences in the recent past has been increased by several folds. Figures 8 and 9 show the earthquake (magnitude $\geq 4.5$ ) occurrences in and around Bangladesh recorded by the United States Geological Survey (USGS) since 1951 (until May 2018). There is a sharp increase in earthquake occurrence over the past five decades, especially since the 1980 's. Most of these 
Fig. 6 Regional tectonic setup and active faults in and around Bangladesh. The plate boundary megathrust represents the boundary between the Indian and Burmese plates. The deformation front of the megathrust is marked after [22]. Other fault boundaries are after [18]. The background map shows the elevation in meter, collected from the Shuttle Radar Topography Mission (SRTM) digital elevation model

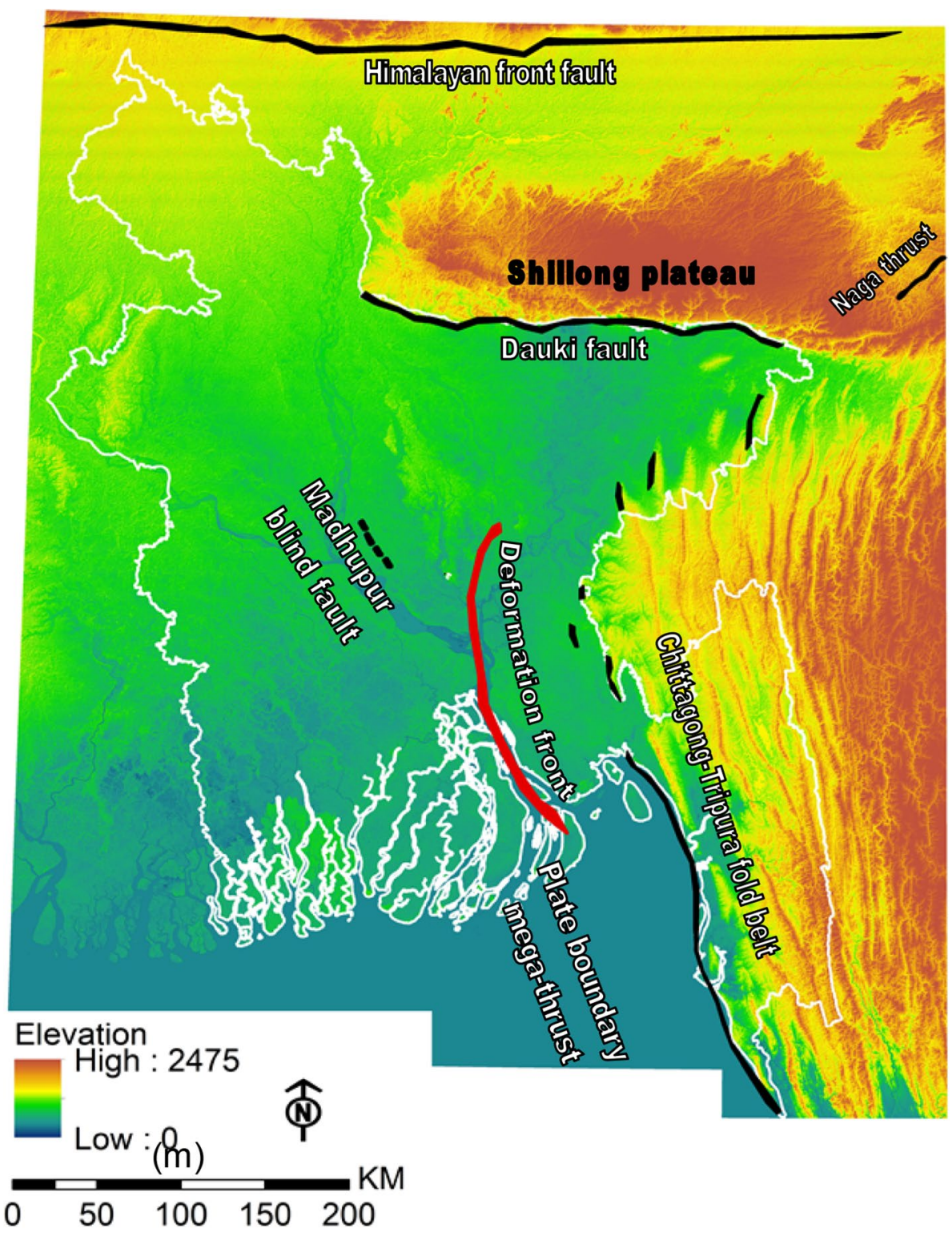

earthquakes have the magnitude in the range of 4.5-5 in Richter scale (Fig. 9b); however, higher magnitude events are also seen to occur. About 3\% of these earthquake occurrences had the magnitude exceeding 6 in Richter scale. More alarmingly, a large number of earthquakes originated close to Dhaka city with $70 \%$ of the total events ( $n=168$ ) having their source located only within $35 \mathrm{~km}$ below the ground surface (Fig. 9c). These data elucidate that there is increasing geological instability in and around Dhaka city, indicating an elevated risk of high-magnitude earthquake occurrence in the coming decades.

\subsubsection{Surficial geology and risk of amplified ground motion}

The earthquake vulnerability in Dhaka has been aggravated by the poor urbanization practice of the city, especially in the areas built over encroached SWB and FP. The earthquake generated primary ground shaking is closely related to the site conditions. The damages to the urban structures during an earthquake depend on the local lithological and hydrogeological conditions [26]. The surficial geology of Dhaka city was divided into six units based on the geomorphological, stratigraphical, and geotechnical characteristics (Fig. 10) [18]. All of Dhaka's surficial deposit is fairly recent, representing Holocene to Modern age in the geological timescale, except the Pleistocene Terrace deposit which covers the middle portion of the city. The Holocene and Modern deposits contain very soft to soft silty and clayey soils and loose sands which pose a significant danger for ground motion in the event of an earthquake [18]. The declined SWB and FP areas of the city were artificially filled with these soft and loose sediments 


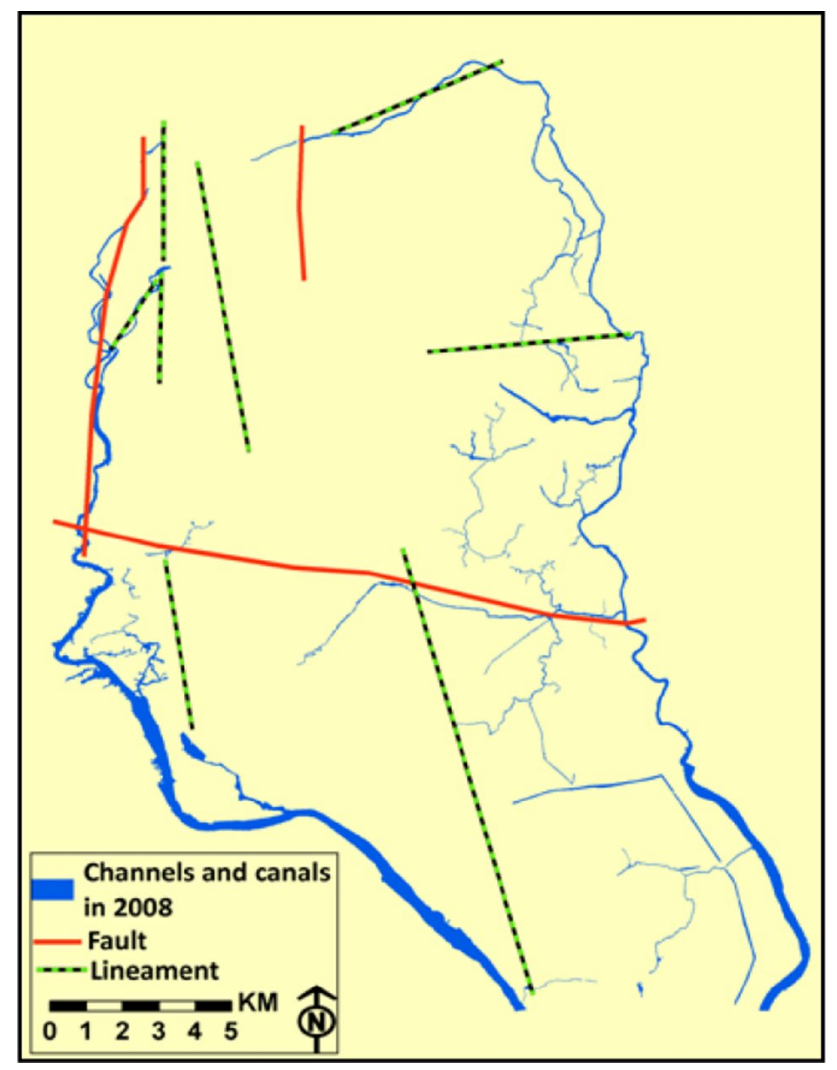

Fig. 7 Shallow subsurface faults and lineaments in Dhaka city (after [25])

with no to minimal ground improvement before urban development. These unconsolidated sediments covering the depleted SWB and FP areas can considerably amplify the shear wave of the earthquake and enhance ground shaking by reducing the speed of the waves and trapping the energy within the sediment layers [27]. Moreover, impedance contrast between these loose sediments and underlying bedrock may contribute to greater ground shaking in the occurrence of an earthquake.

The previous research found a strong relationship between the shear wave velocity of seismic waves and the near surface (top $30 \mathrm{~m}$ ) Holocene soil thickness in Dhaka city [17]. Based on this relationship, a site class map [17] was generated for the city using geophysical measurement and following the guideline of National Earthquake Hazards Reduction Program (NEHRP), the USA [29]. We used this map to identify the site class of the lost SWB and FP areas which were urbanized during the period from 1967 to 2008 (Fig. 11a). We found that $90 \%$ of the lost SWB and FP areas fall in the site class $D$ which represents a shear wave velocity in the top $30-\mathrm{m}$ soil thickness, Vs30 of $180-360 \mathrm{~m} / \mathrm{s}$. The rest of the lost areas is included in the site class $E$, indicating a Vs 30 of $<180 \mathrm{~m} / \mathrm{s}$. The areas with $\mathrm{E}$ class are mainly clustered along the western boundary of the city and found to be intensely urbanized during the field survey. A study in the Dinner region of southwest Turkey found that areas with site class $D$ and $E$ representing poor soil conditions were correlated with the damage distribution of the 1995 Dinner earthquake-an event known for its widespread destruction even due to a moderate-magnitude $(\mathrm{Mg}=6.1)$ earthquake [30]. Mexico City was also devastated after the 1985 earthquake due to the poor soil conditions and faulty urban development, even though the source of the earthquake was $350 \mathrm{~km}$ away from the city center [31]. Thus, we conclude that the
Fig. 8 Earthquake $(M g \geq 4.5)$ occurrences in and around Bangladesh since 1951 (the legend shows the magnitude in Richter scale and depth to the source in $\mathrm{km}$ )

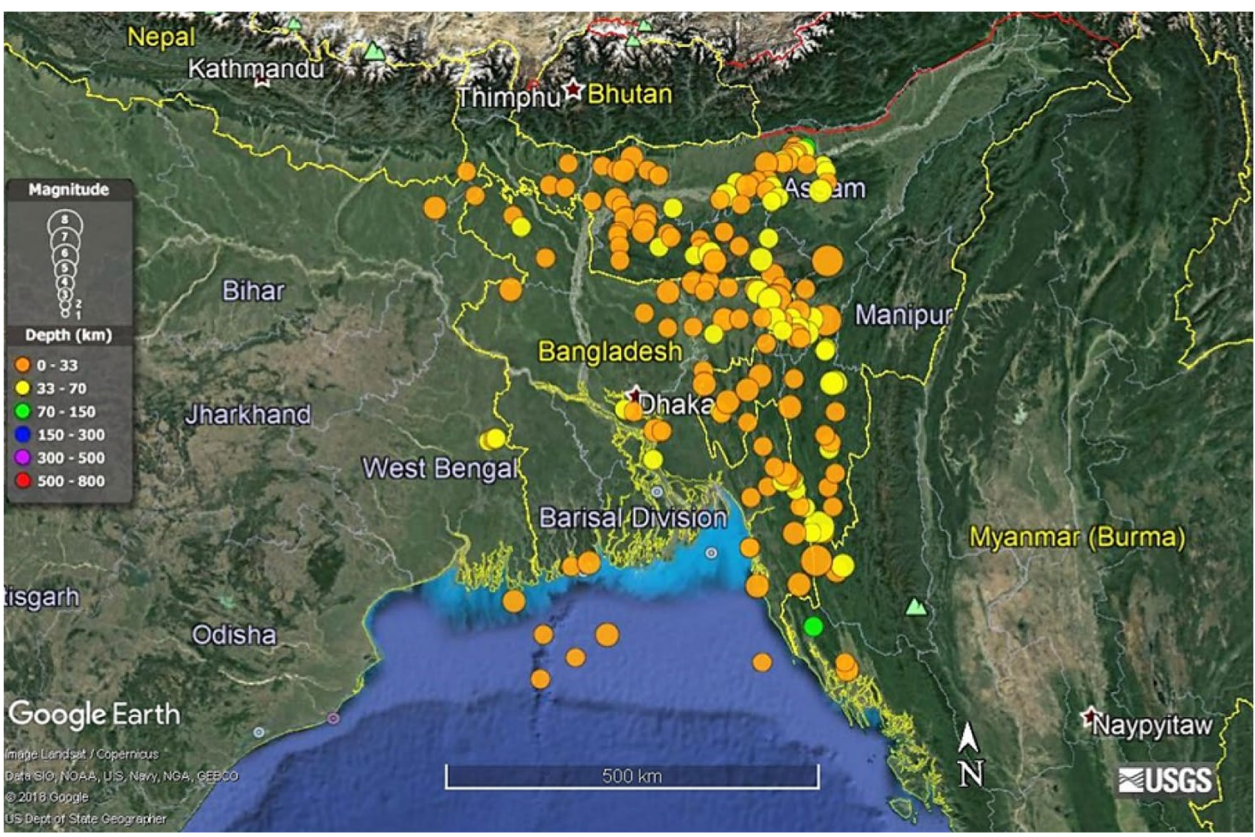


Fig. 9 (a) Earthquake $(M g \geq 4.5)$ events in different years (until May 2018), $n=164 ;$ (b) $\%$ of earthquakes of different magnitudes; (c) \% of earthquake occurrences at different depths. All the data presented in the figures are from the United States Geological Survey (USGS)
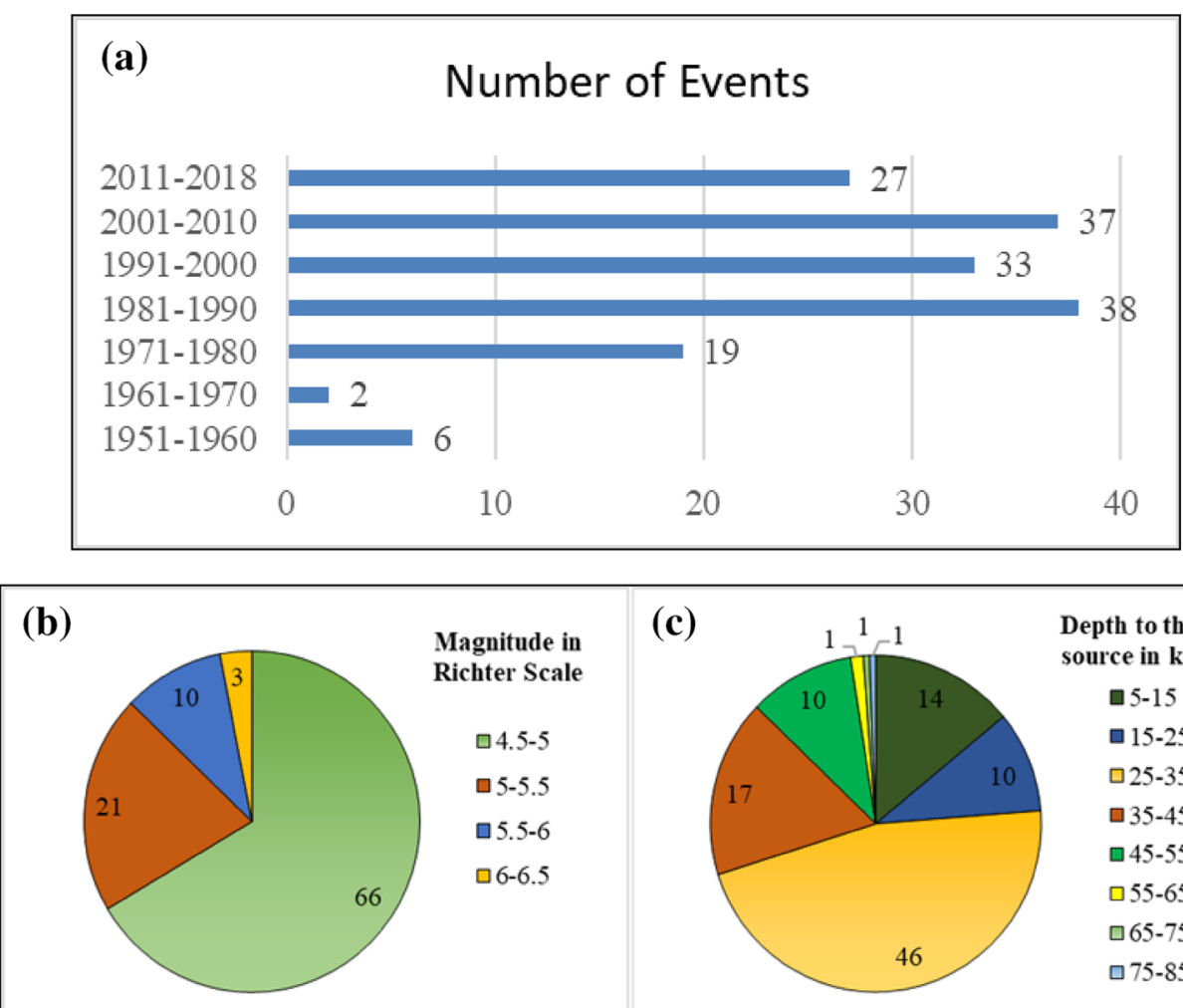

(c)

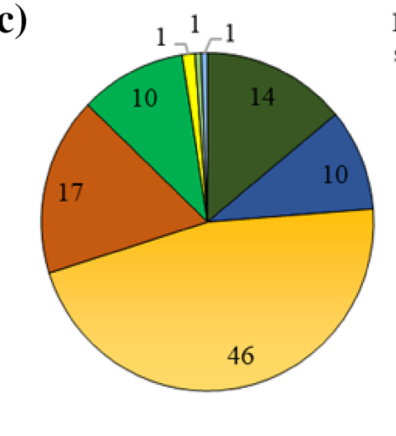

Depth to the source in $\mathrm{km}$ Richter Scale ㅁ.5-5 $\square 5-5.5$ ⒌5-6 6-6.5

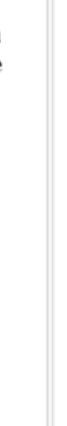

5-15

ㅁ 15-25

25-35

ㅁ 35-45

$\square 45-55$

$\square 55-65$

65-75

$75-85$ urban structures developed on the poorly filled lost SWB and FP areas in Dhaka may face severe destruction due to amplified ground motion in the event of a moderate- to high-magnitude earthquake.

\subsubsection{Risk of earthquake-induced liquefaction}

The ground vibrations of the earthquakes cause compaction of the soft and loose ground materials resulting in large, differential settlements of the ground surface. Such settlements of the ground produce excess hydrostatic pore water pressure and cause liquefaction of the soil as an indirect effect of the earthquake [32]. Liquefaction has the potential to cause extensive damage in areas which were built over unconsolidated soft sediments. It was estimated that river channels, floodplain deposits, and artificially filled uncompacted deposits of age $<500$ years have high to very high susceptibility to liquefaction during strong seismic shaking [33]. As exhibited in this analysis, a large portion of Dhaka city was constructed over young ( $\sim 50$ years old) unconsolidated soft sediments and thus poses considerable concerns for liquefaction hazard. In addition, depth to the groundwater aquifer and seasonal fluctuations of the groundwater table may have a pronounced impact on the liquefaction potential of a site [26]. In most part of Dhaka city, the groundwater table is located at depths $>30 \mathrm{~m}$, but in the floodplain areas near the eastern and western fringe of the city, the groundwater is only at $5-15 \mathrm{~m}$ below the surface and considerably rises during the monsoonal precipitation [34, 35]. Occurrences of such shallow groundwater level in the built-up floodplain areas of the city may modify the shear wave velocity generated by the earthquakes and may cause extensive liquefaction of the ground materials and result in structural damage.

A recent study produced a liquefaction hazard map of Dhaka city [18] based on the liquefaction potential index (LPI) [36] which evaluates the liquefaction hazard of an area as a proportional factor of the thickness of the liquefiable layer and how close the liquefiable layer is from the ground surface. We used this LPI-based map to generate a liquefaction hazard map of the lost SWB and FP areas of Dhaka city (Fig. 11b). LPI values in the lost areas range from 0 to $>15$. We grouped the LPI values into four classes as exhibited in Fig. $11 \mathrm{~b}$. We found that only $1 \%$ of the lost areas fall in the $\mathrm{LPI}=0$ class, while $39 \%, 51 \%$, and $9 \%$ of the lost areas are included in the classes of ' $0<\mathrm{LPI} \leq 5$ ', ' $5<\mathrm{LPI} \leq 15$ ', and ' $\mathrm{LPI}>15$ ', respectively. A large portion in the eastern and western fringes of the city has higher LPI values $(>5)$ and is of significant concern in the event of a high-magnitude earthquake. Moreover, some areas with high LPI values coincide with low Vs30 values. For example, the neighborhoods in the Demra region near the southeastern corner of the city in the Balu river floodplains have 


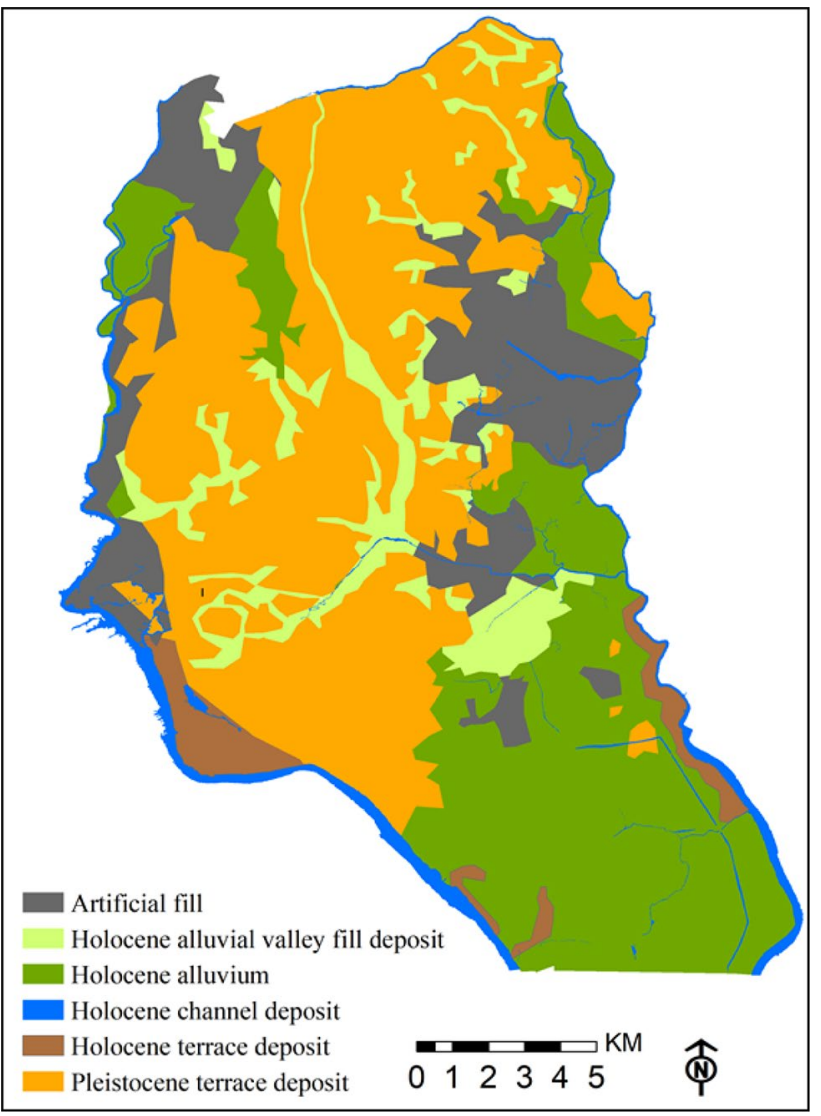

Fig. 10 Surficial geological deposits in Dhaka city-modified from [28]

LPI values $>15$ and Vs30 values $<180 \mathrm{~m} / \mathrm{s}$. Built-up structures in these neighborhoods will be highly susceptible to destruction in the occurrence of earthquakes. A recent study in Kolkata, India, which is part of the same regional geological settings with Dhaka found that $L P I$ value ranges (i.e., $\mathrm{LPI}=0,0<\mathrm{LPI} \leq 5,5<\mathrm{LPI} \leq 15$, and $\mathrm{LPI}>15$ ) estimated in their research agree with the reported liquefaction damages caused by the 1934 Bihar-Nepal earthquake in Kolkata city [37]. Field assessment-based study at several California liquefaction sites also confirmed that surface manifestations of liquefaction are about $58 \%$ and $93 \%$ when $5<\mathrm{LPI} \leq 15$, and $\mathrm{LPI}>15$, respectively [38]. Therefore, a substantial portion ( $60 \%)$ of the built-up SWB and FP areas in Dhaka city may face significant liquefactionrelated destruction as the aftermath of a moderate- to high-magnitude earthquake.

\subsubsection{Mapping the earthquake vulnerability of the depleted SWB and FP areas}

As described above, the lost SWB and FP areas in Dhaka city are highly vulnerable to strong ground motion and liquefaction of earthquakes. It is also evident that surficial geological deposits have a strong connection to both ground motion and liquefaction. Thus, we used the maps of surficial geology, ground motion site class, and liquefaction hazard to map the earthquake vulnerability of the depleted SWB and FP areas in Dhaka city.

We assigned ranking from 1 to 5 to the maps presented in Figs. 10 and 11 with 'rank 1 ' being the least vulnerable to earthquake. To rank the surficial geology map, we used the information presented in [33] where various sedimentary deposits were assessed for their susceptibility to earthquake-related destruction. Accordingly, we assigned 'rank 1' to the Pleistocene terrace deposits, 'rank 2' to the Holocene alluvial valley fill and terrace deposits, and'rank 3 ' to the Holocene alluvium and artificial fill deposits. The current areas with flowing water channels (i.e., Holocene channel deposit in the map) were not considered in the vulnerability assessment. We utilized the site classification described in the guideline of the National Earthquake Hazards Reduction Program (NEHRP), the USA [29] to rank the site class map. There are six classes (A to F) in the NEHRP guideline; thus, we assigned 'rank 4 ' to site class $D$ and 'rank 5 ' to site class $E$. The liquefaction map was ranked based on the $\mathrm{LPI}$ values with ' $\mathrm{LPI}=0$ ' being 'rank $11^{\prime}, 0<\mathrm{LPI} \leq 5^{\prime}$ being 'rank 2', ' $5<\mathrm{LPI} \leq 15$ ' being 'rank 3', and finally, 'LPI $>15$ ' being 'rank 4 '. Once the ranking was assigned, we produced raster maps from each of them and multiplied the raster maps to produce a map of earthquake vulnerability (Fig. 12), where the higher the value, the greater the vulnerability of earthquake.

We found that the earthquake vulnerability score ranges from 4 to 60 for the depleted SWB and FP areas in the city. The southern-most portion of the city has some highest scores in the vulnerability map, while most of the lowest scores are observed in the middle portion of the city where the surficial deposits are composed mostly of Pleistocene sediments. The eastern and western fringes of the city are dominated by the scores ranging from 25 to 40 , indicating significantly high earthquake vulnerability. In addition, the faults and lineaments may considerably increase the earthquake vulnerability if seismic waves are guided along these zones of discontinuities. Amplification of the seismic shocks occurs most at the fault segments, bends, and intersections [39]. Therefore, the vulnerability of earthquake in the depleted SWB and FP areas will be intensified in the zones of differently oriented faults and lineaments [40].

\section{Conclusion}

Dhaka city experienced a substantial loss of SWB and FP during the period from 1967 to 2008. The depleted areas were used for constructing urban infrastructures with no 


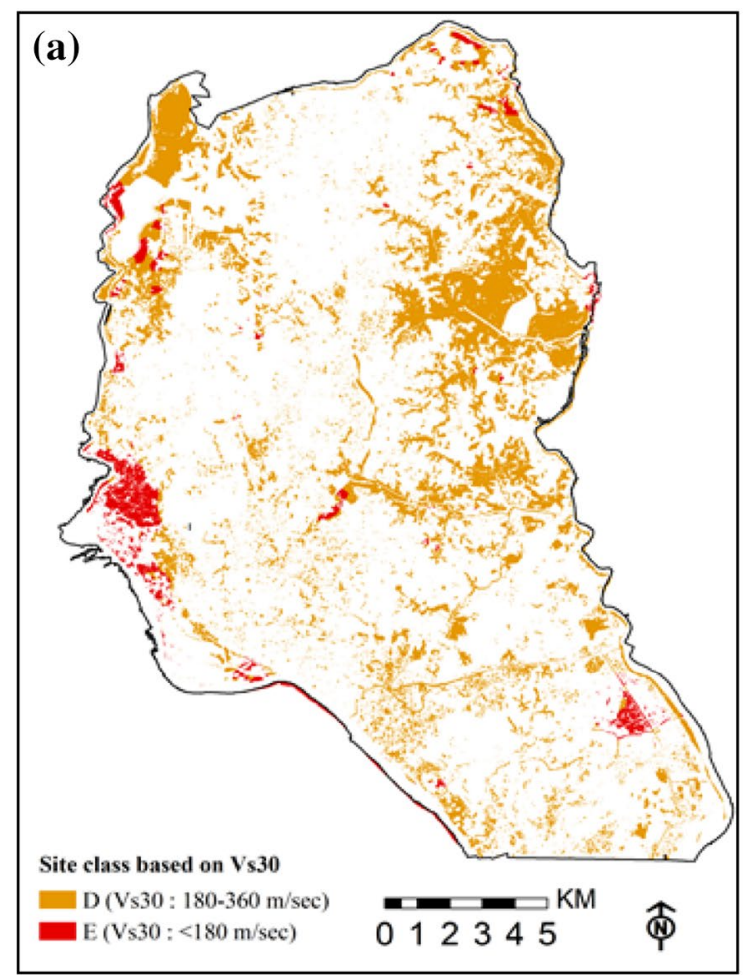

Fig. 11 a Ground motion site class map of the depleted surface water body and floodplain areas of Dhaka city based on the shear wave velocity in the top $30 \mathrm{~m}$ of soil thickness (Vs30)-modified

to minimal ground improvement and thus pose a significant concern for earthquake-related hazards since the city is part of a highly active tectonic region. We observed that small-scale earthquake occurrences in this region have been increased by several folds in the past few decades, raising the likelihood of high-magnitude earthquake occurrence in the near future. The built-up SWB and FP areas in Dhaka city are prone to both strong ground shaking and liquefaction of earthquake. Our vulnerability map showed that a significant portion of the urbanized SWB and FP areas is highly susceptible to earthquake-related hazard, especially the areas near the southern boundary of the city. The eastern and western fringes of the city also

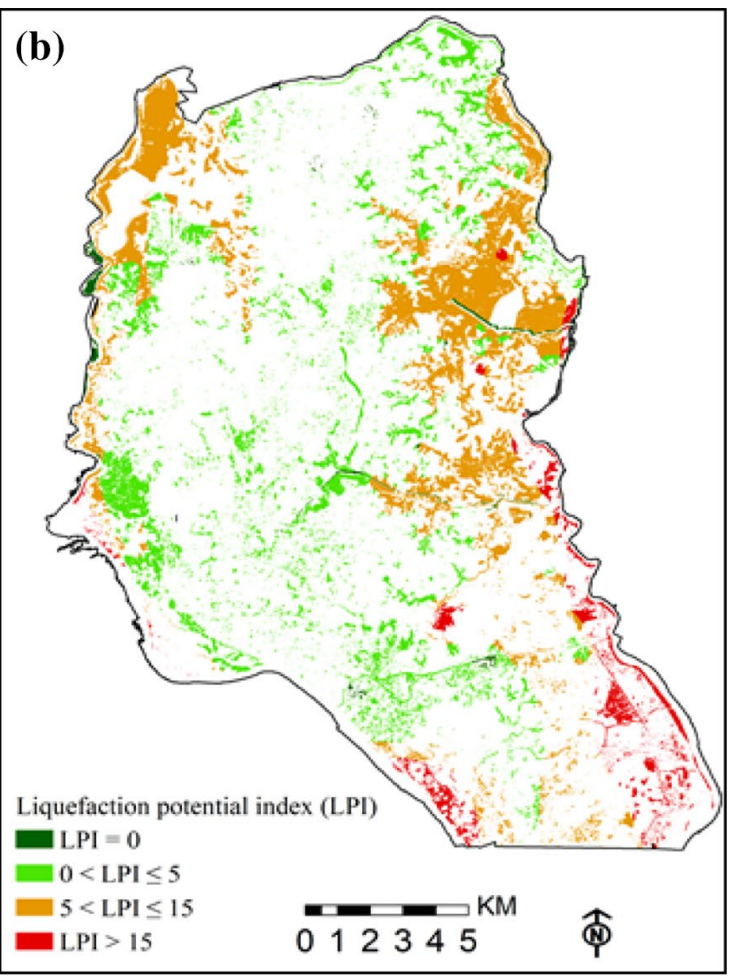

from [17]. b Liquefaction hazard map of the depleted surface water body and floodplain areas of Dhaka city based on liquefaction potential index (LPI)—-modified after [18]

scored highly in the vulnerability map. However, the vulnerability mapping in our study did not have the scope to consider demographical and other socioeconomic information; hence, any future assessment incorporating such data will enhance the utility of vulnerability map.

The spatially explicit outcomes of our study can be utilized for developing effective preparedness programs which may minimize the loss during the occurrence of high-magnitude earthquakes. Moreover, our research urges to improve the current city development practice and protect the natural surface water body and floodplain areas for a sustainable future of the city. 


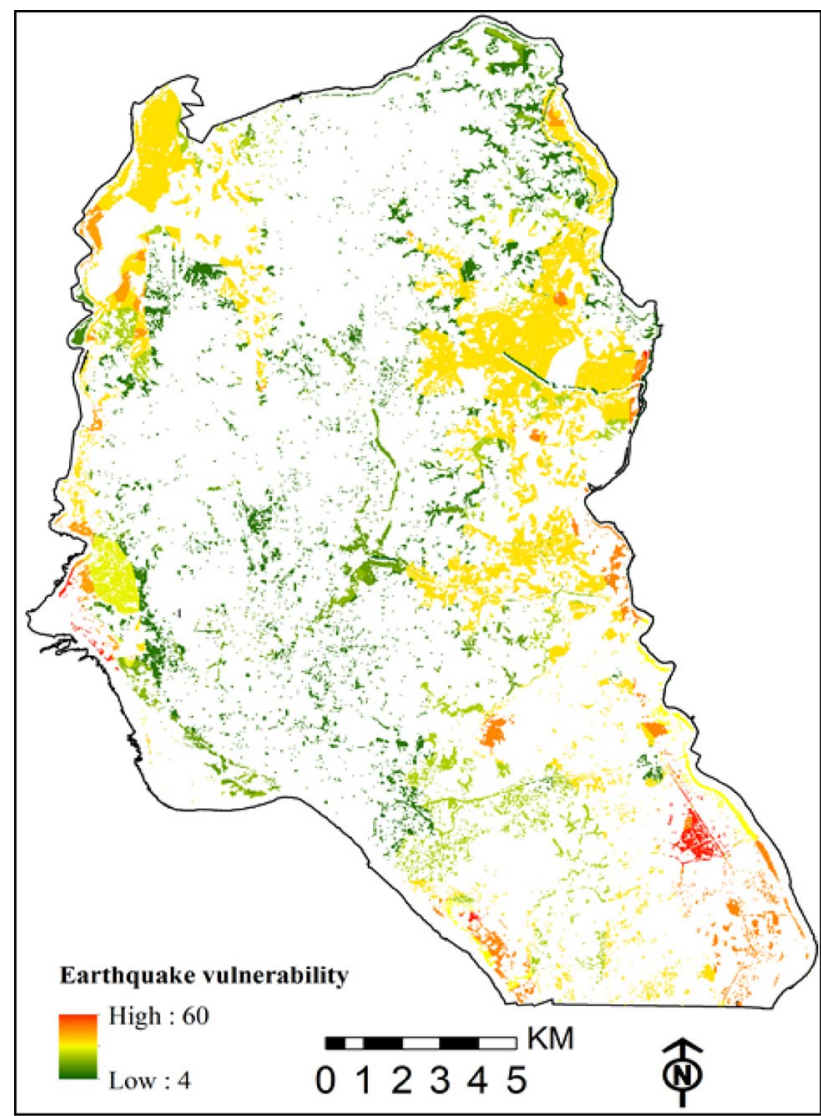

Fig. 12 Earthquake vulnerability map of the depleted surface water body and floodplain areas of Dhaka city

Acknowledgements The authors would like to thank the Center for Environmental and Geographic Information Services (CEGIS), Government of Bangladesh for data and technical help. The authors also acknowledge the support from the Department of Geology, University of Dhaka.

\section{Compliance with ethical standards}

Conflict of interest On behalf of all authors, the corresponding author states that there is no conflict of interest.

\section{References}

1. Heilig GK (2012) World urbanization prospects: the 2011 revision. New York: United Nations, Department of Economic and Social Affairs (DESA), Population Division. Popul Estim Proj Sect

2. Dugan $P$ (1993) Wetlands in danger: a world conservation atlas. Oxford university press, New York

3. JICA (1991) Master plan for Greater Dhaka Protection Project (Study in Dhaka Metropolitan Area), FAP 8A, Main Report and Supporting Reports I and II. Dhaka

4. Dewan AM, Kumamoto T, Nishigaki M (2006) Flood hazard delineation in Greater Dhaka, Bangladesh using an integrated
GIS and remote sensing approach. Geocarto Int 21:33-38. https ://doi.org/10.1080/10106040608542381

5. Mahmud MS, Masrur A, Ishtiaque A et al (2011) Remote sensing \& GIS based spatio-temporal change analysis of wetland in Dhaka city, Bangladesh. J Water Resour Prot 3:781-787. https ://doi.org/10.4236/jwarp.2011.311088

6. Steckler MS, Akhter SH, Lamont LS et al (2016) Locked and loading megathrust linked to active subduction beneath the Indo-Burman Ranges. Nat Geosci 9:615-618. https://doi. org/10.1038/NGEO2760

7. Cardona C, Davidson R, Villacis C (1999) Understanding urban seismic risk around the World, a final report on the Comparative Study. A Proj United Nations RADIUS Initiat IDNDR, Publ by Geo Hazards Int

8. Paul BK, Bhuiyan RH (2010) Urban earthquake hazard: perceived seismic risk and preparedness in Dhaka city, Bangladesh. Disasters 34:337-359

9. Govindaraju L, Bhattacharya S (2012) Site-specific earthquake response study for hazard assessment in Kolkata City, India. Nat Hazards 61:943-965

10. Tsuda K, Steidl J, Archuleta R, Assimaki D (2006) Site-response estimation for the 2003 Miyagi-Oki earthquake sequence considering nonlinear site response. Bull Seismol Soc Am 96:1474-1482

11. Paul S, Li J, Wheate R, Li (2018) Application of object oriented image classification and Markov chain modeling for land use and land cover change analysis. J Environ Inform 31:30-40. https://doi.org/10.3808/jei.201700368

12. Huq S, Alam M (2003) Flood management and vulnerability of Dhaka city. In: Building safer cities: the future of disaster risk. The World Bank, Washington, D.C, pp 121-135

13. BBS BB of S (2011) Bangladesh statistical yearbook 2010. Bangladesh Bureau of Statistics Dhaka, Dhaka

14. Islam I (2009) Wetlands of Dhaka Metro area: a study from social, economic, and institutional perspectives. AH Development Publishing House Dhaka, Dhaka

15. Weng Q (2002) Land use change analysis in the Zhujiang Delta of China using satellite remote sensing, GIS and stochastic modelling. J Environ Manag 64:273-284

16. Sawaya KE, Olmanson LG, Heinert NJ et al (2003) Extending satellite remote sensing to local scales: land and water resource monitoring using high-resolution imagery. Remote Sens Environ 88:144-156. https://doi.org/10.1016/J. RSE.2003.04.006

17. Rahman Z, Kamal ASMM, Siddiqua S (2018) Near-surface shear wave velocity estimation and Vs30 mapping for Dhaka city, Bangladesh. Nat Hazards 92:1687-1715. https://doi. org/10.1007/s11069-018-3266-3

18. Rahman Z, Siddiqua S, Kamal ASMM (2015) Liquefaction hazard mapping by liquefaction potential index for Dhaka. Eng Geol 188:137-147. https://doi.org/10.1016/j.enggeo.2015.01.012

19. Akhter SH (2010) Earthquakes of Dhaka. Asiatic Society of Bangladesh, Dhaka

20. Steckler MS, Akhter SH, Seeber L (2008) Collision of the GangesBrahmaputra Delta with the Burma Arc: implications for earthquake hazard. Earth Planet Sci Lett 273:367-378

21. Mullick M, Riguzzi F, Mukhopadhyay D (2009) Estimates of motion and strain rates across active faults in the frontal part of eastern Himalayas in North Bengal from GPS measurements. Terra Nova 21:410-415

22. Maurin T, Rangin C (2009) Structure and kinematics of the IndoBurmese Wedge: recent and fast growth of the outer wedge. Tectonics 28:1-21

23. Alam K, Aurangzeb M (1975) Geological environment for greater Dacca City. In: Conference issue of the Bangladesh Geological Society. pp 34-36 
24. Alam K (1988) Geology of Madhupur Tract and its adjoining areas in Bangladesh. Geological Survey of Bangladesh

25. Shams N (1999) Urban geology of Dhaka city for geohazard mitigation and development planning. University of Dhaka, Dhaka

26. Theilen-Willige B (2010) Detection of local site conditions influencing earthquake shaking and secondary effects in SouthwestHaiti using remote sensing and GIS-methods. Nat Hazards Earth Syst Sci 10:1183

27. Pratt TL, Horton JW, Muñoz J, et al (2017) Amplification of earthquake ground motions in Washington, DC, and implications for hazard assessments in Central and Eastern North America. Geophys Res Lett 44:12150-12160

28. (CDMP) CDMP (2009) Seismic hazard and vulnerability assessment of Dhaka, Chittagong and Sylhet city corporation areas. Final Report. Dhaka, Bangladesh

29. Council BSS, (US) NEHRP, Agency USFEM (2004) NEHRP recommended provisions for seismic regulations for new buildings and other structures (FEMA 450). BSSC, Washington

30. Kanlı Al, Tildy P, Prónay $Z$ et al (2006) VS30 mapping and soil classification for seismic site effect evaluation in Dinar region, SW Turkey. Geophys J Int 165:223-235

31. Campillo M, Gariel JC, Aki K, Sanchez-Sesma FJ (1989) Destructive strong ground motion in Mexico City: source, path, and site effects during great 1985 Michoacán earthquake. Bull Seismol Soc Am 79:1718-1735

32. Youd TL, Idriss IM (2001) Liquefaction resistance of soils: summary report from the 1996 NCEER and 1998 NCEER/NSF workshops on evaluation of liquefaction resistance of soils. J Geotech Geoenviron Eng 127:297-313

33. Youd TL, Perkins DM (1978) Mapping liquefaction-induced ground failure potential. J Soil Mech Found Div 104:433-446
34. IWM (2008) Resource assessment and monitoring of water supply sources for Dhaka city: final report part 2 for Dhaka water supply and sewerage authority. Dhaka, pp 1-33

35. Hermann KM (2016) Groundwater modelling in Dhaka: a study to improve an existing groundwater model of Dhaka and to explore its applications

36. Iwasaki T (1978) A practical method for assessing soil liquefaction potential based on case studies at various sites in Japan. In: Proceedings of the second international conference on microzonation safer construction research application, 1978. pp 885-896

37. Nath SK, Srivastava N, Ghatak C et al (2018) Earthquake induced liquefaction hazard, probability and risk assessment in the city of Kolkata, India: its historical perspective and deterministic scenario. J Seismol 22:35-68

38. Toprak S, Holzer TL (2003) Liquefaction potential index: field assessment. J Geotech Geoenviron Eng 129:315-322

39. John B (2018) Importance of geological studies in earthquake hazard assessment. In: Integrating disaster science and management. Elsevier, Amsterdam, pp 27-40

40. Theilen-Willige B, Wenzel H (2009) Local site conditions influencing earthquake shaking intensities and earthquake related secondary effects-A standardized approach for the detection of potentially affected areas using remote sensing and GISmethods.-10. Forum Katastrophenvorsorge, Katastr

Publisher's Note Springer Nature remains neutral with regard to jurisdictional claims in published maps and institutional affiliations. 